DOI https://doi.org/10.30525/978-9934-26-075-9-32

\title{
ANALYSIS OF RELATIONSHIPS BETWEEN CHILDREN'S AND THEIR PARENTS' BEHAVIORAL HABITS AND PERIODONTAL STATUS, ORAL HYGIENE IN SCHOOL-AGE CHILDREN WITH DIABETES TYPE I DIABETES MELLITUS
}

\author{
Sheshukova O. V. \\ Doctor of Medical Sciences, Professor, \\ Head of the Department of Pediatric Dentistry \\ Ukrainian Medical Stomatological Academy \\ Kuz I. 0. \\ Postgraduate Student at the Department of Pediatric Dentistry \\ Ukrainian Medical Stomatological Academy \\ Maksymenko A. I. \\ Candidate of Medical Sciences, \\ Associate Professor at the Department of Pediatric Dentistry \\ Ukrainian Medical Stomatological Academy \\ Polishchuk T. V. \\ Candidate of Medical Sciences, \\ Associate Professor at the Department of Pediatric Dentistry \\ Ukrainian Medical Stomatological Academy \\ Mosiienko A. S. \\ Assistant at the Department of Pediatric Dentistry \\ Ukrainian Medical Stomatological Academy \\ Poltava, Ukraine
}

The presence of type I diabetes mellitus in children is the main risk of inflammatory processes in periodontium [1, p. 80-86]. The following characteristics are inherent for children with endocrine pathology: in imusheny frequent eating of food (children with type I diabetes mellitus often use fastacting carbonhydrates such as honey, or candy to prevent hypoglycemia) [5, p. 39-44]; violation of self-cleaning processes in the oral cavity; decrease in the resistance of the macroorganism and local protection factors; accumulation of dental plaque; the minimum level of anti-infectious protection of the oral 
cavity; increased activity of anaerobic microbial flora; hyposalivation etc [2, p. 1155-1159].

The aim of this study was to determine the links behavioral habits, periodontal status and oral hygiene in children of primary school age with type I diabetes (type I diabetes) and somatically healthy children of the same age group.

Materials and methods. We have examined 82 children (6-12 years): 56 children with diabetes type I and 26 somatically healthy children. The simplified hygienic index OHI-S (Green, Vermillion, 1964), the PMA index modified by Parma (1960), the bleeding index according to Loe, Silness (1967) (gingival index), and the bleeding index (Muhleman H. The R. (1971)). The study participants and their guardians (parents) answered the question «Dental questionnaire for children and parents» (copyright registration certificate, dated January 24, 2020).

Results and their discussion. All the children were divided into 4 groups according to the presence of diabetes I type and chronic catarrhal gingivitis (CCG).

The results of a simplified index of oral hygiene OHI-S (GreenVermillion) are given below. This index is $0.69 \pm 0.06$ points (good level of hygiene) in somatically healthy children with healthy gums. The OHI-S (Green-Vermillion) is $1.60 \pm 0.06$ and $0.88 \pm 0.07$ points in healthy children with CCG and children with I type diabetes mellitus and healthy gums (satisfactory oral hygiene). OHI-S (Green-Vermillion) in a group of children with diabetes I type and CCG is $1.87 \pm 0.05$ points (bad oral hygiene).

We found statistically significant difference between patients with type 1 diabetes mellitus and healthy children according to periodontal indices and bleeding index. Both the bleeding index and the periodontal indices in patients with healthy gums (both somatically healthy and children with type I diabetes) indicate the absence of inflammation. PMA is $20.50 \pm 0.83 \%$, and gingival index of Loe, Silness is $0.84 \pm 0.05$ points, bleeding index is $0.71 \pm 0.05$ points in somatically healthy children with CCG (mild gingivitis). The totality of the above-mentioned indices in children with CCG and DM I type correspond to the average severity of gingivitis (PMA- $40.47 \pm 0.96 \%$, gingnival index (GI) is $1.83 \pm 0.04$ points, and bleeding index is $1,07 \pm 0.05$ points.

We can conclude that protective mechanisms in children with diabetes are changed based on the results of our research work.

The next stage of our research work was the analysis of answers on the questionnaire for children and their parents, named «Dental Questionnaire for Children and Parents», developed by us (copyright registration certificate, dated January 24, 2020). The questionnaire consists of two parts. Each of them has more, than 20 questions (parents should answer both of them). The first 
part is about children, and the second is about their caregivers (parents). We present here only some questions, that deserve special attention, in our opinion.

For example, to the question "When?" and "For what the reason why did you go to the dentist?" (regarding to the child), 37.8\% of parents gave the answer" Once a year", 32.93\% - "2 times a year", the rest $-29.27 \%$ were 3 or more times. The reason for the visit in $36.59 \%$ of cases was pain and problems with teeth and gums; $34.15 \%$ of parents took their children to re-treatment, and only $29.27 \%$ of children approached their parents for the purpose of routine examination. The frequency of visits per year did not differ in children with type I diabetes and somatically healthy children. It should be noted that almost half of the respondents with type I diabetes ( 24 out of 56 children with type I diabetes) cited the presence of dental problems as the reason.

To the question «Does your child brush his teeth himself?» $89.24 \%$ answered «Yes». Only $28.05 \%$ of parents answered the question «Do you control the brushing of your child's teeth?» «Yes». To the question "Do you brush your child's teeth?" only $10.98 \%$ answered "Yes". There was no difference in the answers to the first 2 questions about self-cleaning of teeth between children with type I diabetes and somatically healthy children. However, it should be focused that only parents of healthy children with healthy gums said "Yes" to the question "Do you help to brush your child's teeth?". In this group, the best indicators of oral hygiene were noted, namely the OHI-S (Green-Vermillion) hygiene index $-0.69 \pm 0.06$ points (compared with children with type I diabetes, their indicators correspond to bad oral hygiene, and exactly $1.87 \pm 0.05$ points).

"Have you consulted a dentist about treating your child's gums?" Only four parents said «Yes» (all of them are parents of children with type I diabetes), this is only $4.88 \%$. It is worth noting that most of the children whose parents took part in the survey have CCG of varying severity. Majority of parents are completely ignorant of periodontal diseases that can appear in children and adolescents.

The answer «Misunderstanding of pathological processes (I don't understand why dental diseases appear)» was given by $53.66 \%$ of the respondents to the question "What is holding you back in time to receive dental prophylaxis (treatment) for your child?». «I have to go to the dentist many times with my child» answered $18.29 \%$ of parents, and those who answered "The price of dental treatment" were $2805 \%$. More than half of parents of children with type I diabetes mellitus (38 responders among 56) do not understand how dental diseases, including gingivitis, develop. Special attention should be given to this fact. 
To the question «What kind of toothbrush does your child use?» $8.54 \%$ answered «Electric», 91.46\% answered «Manual». "Does your child use an irrigator, flos, or other special dental devices?" all responders answered "No". All who answered "Electric" belonged to the group of children with type I diabetes and healthy gums.

We also asked "How would you and your children like to receive useful and interesting information about dental diseases?" "Educational programs in schools" - answered $15.85 \%$ of parents, "Internet" - 71.95\%, "Television" $12.20 \%$.

Conclusions. We found that children with type I diabetes have a worse oral hygiene condition than somatically healthy children; its level can be assessed from unsatisfactory to bad according to various indices [3, p. 39-44]. Children with diabetes mellitus have much degree of gum inflammation and much more gum bleeding compared to healthy children of the same age $[4, \mathrm{p}$. 122-126].

The results of our research work indicate that, unfortunately, the overwhelming majority of parents are not aware of the maintenance of highquality oral hygiene by their children, they do not understand the mechanisms of development of either periodontal disease or other dental diseases. An astonishingly large percentage of parents do not control the brushing of their children's teeth, and therefore do not help children to brush their teeth.

\section{References:}

1. Шешукова О.В., Кузь I.О. Аналіз індексів гігієни і пародонтальних індексів у дітей із цукровим діабетом I типу. Украӥнський стоматологічний альманах. 2020. № 4. С. 90-95.

2. Geetha S., Pramila M., Jain K., Suresh C. Oral health status and knowledge among 10-15years old type 1 diabetes mellitus children and adolescents in Bengaluru. Indian J Dent Res. 2019. № 30(1). P. 80-86.

3. Ismail A.F., McGrath C.P., Yiu CK.Y. Oral health status of children with type 1 diabetes: a comparative study. J Pediatr Endocrinol Metab. 2017. № 30(11). P. 1155-1159.

4. Maksymenko A.I., Kuz I.O., Sheshukova O.V. Dental status analysis in children with insulin-dependent diabetes mellitus. New trends and unresolved issues of preventive and clinical medicine: materials of International scientific and practical conference (Lublin, September 25-26, 2020). Lublin, 2020. P. 1. P. 137-140.

5. Pachoński M., Jarosz-Chobot P., Koczor-Rozmus A., Łanowy P. Dental caries and periodontal status in children with type 1 diabetes mellitus. Pediatr Endocrinol Diabetes Metab. 2020. № 26(1). P. 39-44. 